\title{
DECISION SUPPORT SYSTEM FOR ROOFTOP SOLAR IN THE BRONX
}

\author{
EVANGELOS KATSAMAKAS (corresponding author) \\ Gabelli School of Business, Fordham University \\ New York, New York, U.S.A. \\ katsamakas@fordham.edu
}

CLAIRE SIEGRIST

Gabelli School of Business, Fordham University

New York, New York, U.S.A.

csiegrist1@fordham.edu

\begin{abstract}
This paper proposes a decision support system for the economic and technical feasibility of operating distributed photovoltaics in Bronx, N.Y. Existing research shows that distributed generation (DG) is a more effective way of reengineering the electricity system to integrate more renewable sources compared to a centralized, fossil fuel-based system. The viability of decentralizing electricity production with solar, however, is location-dependent and does not achieve the economies of scale that centralized systems enjoy. To determine the economic feasibility of DG with photovoltaics at a regional level, the system proposed here accounts for the relative cost to consumers and supply of electricity from the grid based on a framework developed by the National Renewable Energy Laboratory. The variables that were considered include regional demand, space capacity, fixed and variable costs to consumers, supply costs, and existing government support programs. Thus, drawing on data reported by the New York City government and other sources, this paper found that rooftop solar is economically feasible with existing government support programs and can reduce overall emissions despite being unable to meet the Bronx's peak demand. The proposed system can therefore be adopted and used by public and/or private local decision-makers from other similar locations.
\end{abstract}

\section{KEYWORDS}

solar energy; decision support system; business intelligence; economic feasibility; technical feasibility; distributed generation 


\section{INTRODUCTION}

The world's energy system has attracted international attention because of its universal impact on and criticality for the future of human civilization. Global trends such as urbanization, industrialization, and digitalization are inherently connected to innovations in energy that reshape the landscape of its demand (World Economic Forum, 2017). Yet technological advancements in energy production and consumption could support such changes-according to a Bloomberg New Energy Finance study, for example, solar energy can economically meet half of the world's electric power needs by 2025. New sources of capital, in addition, have also made energy innovation possible. Private investors, for instance-rather than traditional government or public market support-have invested $\$ 200$ billion in the energy sector over the last five years (World Economic Forum, 2017).

Much of the infrastructure we take for granted, however, is aging at the same time. According to the New York State Energy Research \& Development Authority (NYSERDA), 84\% of New York State's electric grid infrastructure predates the 1980s. Current power sources may even be slated for shutdown, such as the Indian Point nuclear plant which supplies $25 \%$ of New York City's electricity. It is scheduled to be closed down in 2021 (McGeehan, 2017).

In response to these trends and environmental concerns associated with fossil fuels, many state and federal governments have set lofty targets for power diversification and greenhouse gas reduction. They also offer financial incentives to encourage residents and businesses to reach these goals; such incentives, by some accounts, could, for example, offset the installation costs of solar by upwards of $90 \%$ (EcoMen Solar, 2016). These programs, therefore, suggest both a supportive political environment for renewables and an opportunity for investment.

The cost of renewable energy technology is declining as well. The National Renewable Energy Lab (NREL), for example, reported that the installation cost of both residential and commercial solar decreased by 240\% from 2009 to 2016 (Brown et al., 2016). Renewable power assets, including solar, are nearing price parity with current fossil fuel-based sources as a result, and they will be cheaper than fossil fuels and offer significant investment opportunities that also address structural and environmental concerns if this trend continues. As we stand, therefore, at this convergence of trends in the energy sector, it is critical to understand available technologies in energy as well as the investment opportunities related to them. 
One promising technological direction is distributed generation (DG). As defined by the Federal Energy Regulatory Commission (FERC), distributed generation is a "variety of technologies that generate electricity at or near where it will be used.... Distributed generation may serve a single structure, such as a home or business, or it may be part of a microgrid (a smaller grid that is also tied into the larger electricity delivery system)..." Unlike our current centralized system which relies on few inputs and long distances between producer and consumer, distributed generation is decentralized, with many inputs that are local to the point of consumption. Figure 1 in Farrell (2011) compares centralized and decentralized power systems.

Distributed generation as a concept is not new-energy production was decentralized even before the $20^{\text {th }}$ century. Utility providers who served locally, however, began to realize the economies of scale that were achievable by centralizing their delivery mechanisms. This eventually led to our centralized system in use today (EPA, n.d.). Decentralizing energy production today, then, would require significant investment given the economies of scale achieved by centralized systems. Nevertheless, DG offers two primary benefits: improved reliability due to localization and increased potential for integration of renewables into the energy supply. According to the U.S. Energy Information Administration, nearly $10 \%$ of energy produced is lost in transmission. DG mitigates these losses significantly by reducing transmission distance; energy lost in transmission is thereby reduced given that power sources are closer to the point of consumption. DG also increases the potential for incorporating renewable power sources into the energy supply. There are more opportunities to integrate solar, wind, or hydroelectric given a wider range of possible energy sources (U.S. Department of Energy, 2007).

Distributed generation with solar in particular could address a number of energy concerns and provide an investment opportunity. The actual feasibility and potential of distributed solar, however, is highly location dependent. Critical determinants vary due to weather patterns, solar radiation, installation costs, and electricity prices. Assessments are required at the regional level to determine with accuracy whether or not distributed solar is feasible and if other sources should be explored.

The objectives of this study are twofold. First, it seeks to create a model that combines technical and economic feasibility concerns, one that can provide investors and policymakers with insight into the costs and benefits of installing distributed solar on a regional level. Technical feasibility accounts for real-world 
geographic constraints and system performance while economic feasibility is the difference between the value of electricity that would have been consumed from the grid otherwise and the capital cost of installing the photovoltaic (PV) system (Brown et al., 2016). Second, this study seeks to apply this model to Bronx, N.Y. in an effort to determine the technical and economic feasibility of distributed solar in that borough. The key research question is, "Is operating distributed photovoltaics technically and economically feasible in the Bronx?"

This study focuses on grid-connected, distributed photovoltaics (DPV). "Gridconnected" DPV means that the electricity generated by solar panels is used by the building and any surplus is sent into the grid; this surplus electricity can then be used by any other consumer. Thus, unlike stand-alone configurations, grid-connected systems rarely include storage (Blair et al., 2014). Grid-connected, moreover, means that the system owner's utilities will not be free. Demand charges will remain because the system relies on grid infrastructure; supply charges, however, will be zero (CUNY, n.d.).

"Distributed" refers to rooftop systems—space for ground-mounted distributed systems was not accounted for given that the area of study was in a dense urban setting. "Photovoltaics" means that solar energy rather than solar thermal, which generates heat, is used for electricity production. The scope of this study does not include other types of DG technologies such as wind, hydroelectric, biomass, or utility-scale PV. Finally, this study considers these factors on a local level such as that of a municipality or borough. It is not intended for assessments of entire nations or individual properties.

While the body of knowledge regarding DPV is significant (see Literature Review below), there are many gaps to be addressed. This study tackles two: 1) there is no model that ties technical capacity with cost estimates at a regional level, and 2) there are no studies of this kind on the Bronx, or on any another large urban area for that matter.

For the first gap, tying technical feasibility with cost estimates, there are no studies or models that calculate installation costs based on estimated system parameters and output beyond single properties. Proving the necessary energy and economic efficiency for regional investment, therefore, is an open research topic. 
This paper seeks to close this gap to obtain a more comprehensive understanding of the value of investing in DPV on a regional level.

Second, there are no studies of DPV potential in the Bronx or a large urban area. A focused, regional study is thus required to understand rooftop solar potential in a borough like the Bronx. The determinants of technical and economic feasibilityrooftop availability, solar radiation, installation costs, government policies, and electricity prices, for instance-are highly location-dependent. As such, while many other sites have not been assessed, the Bronx was chosen because it hosts a mix of residential and commercial spaces and is an example of a dense urban area.

\section{LITERATURE REVIEW}

The body of knowledge regarding distributed generation, photovoltaics, and the economics of renewables has been growing rapidly through public, academic, and private research, particularly since the energy crisis of the 1970s (Sullivan, Cannon, Burton, Johnson, \& White, 2014). To understand the current state of these domains, this literature review was conducted in four parts (the structure is shown in Figure 1): 1) affirming the necessity and relevance of renewables for our energy system; 2) validating the technical feasibility and availability of DPV technology; 3) current models for technical and economic assessment of renewables; and 4) existing studies of regional solar assessment.

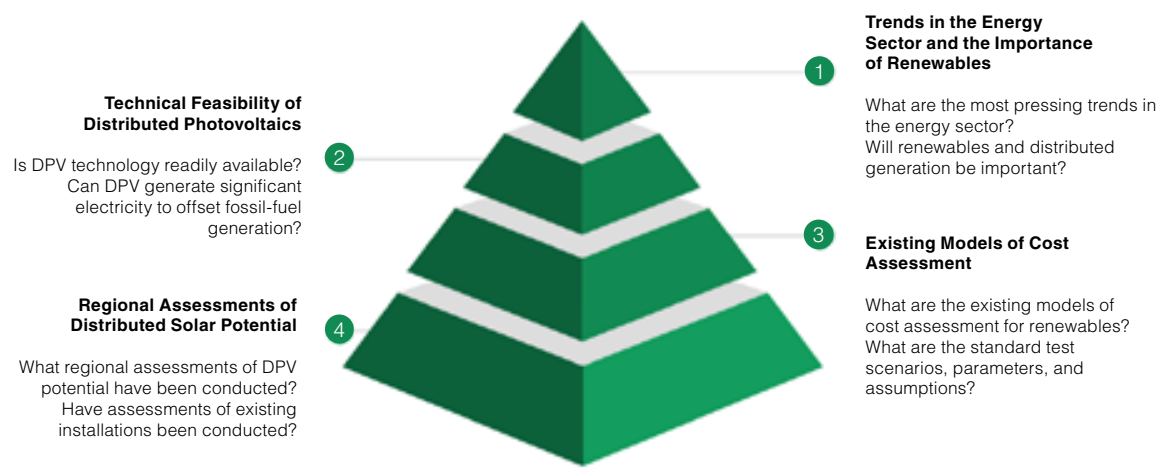

Figure 1: Structure of literature review. 
Trends in the Energy Sector and the Importance of Renewables

The World Economic Forum report (2017) sought to identify global trends, possible "game changers," and implications in the world's energy system. These trends included urbanization, technology cost reductions, advancements in materials, and increased socio-political commitment to the environment, all of which could transform how energy is produced and consumed, such as in advanced energy acceleration and system fragmentation. Such changes have implications for business, government, and society, necessitating new strategies, business models, and private-public collaboration. Moreover, the report placed renewables, and specifically decentralized energy, firmly at the top of global energy priorities. Indeed, while solar was one of many technologies discussed, the findings in the report affirmed DPV's relevance for further research and understanding of implementation potential in existing urban infrastructure.

Pérez-Arriaga et al. (2016) sought to address several drivers of change in power systems, including the growth of renewable energy sources, efforts to decarbonize the energy system, and the increasing interconnectedness of critical infrastructure such as transportation and communications. Four key areas of research were developed: 1) understanding how distributed energy sources affect the operation of power systems, 2) a framework for efficient market design, 3) competition between centralized and distributed resources, and 4) a policy toolkit for the future power system. Data for this analysis was collected from academic and industry publications rather than from proprietary measurements. The study expressed the importance and relevance of distributed generation for the power system of the future. Finally, this collaborative research among 23 organizations confirmed the validity and influence of renewable energy sources already evident in today's power system.

Sullivan et al. (2014) offered a high-level overview of distributed generation's potential economic benefits for both commercial and industrial end users. The paper described how and why DG has grown since the 1970s due to federal incentives, corporate green efforts, and declining installation costs. It also discussed ways in which DG is becoming more viable for commercial end users, including the leasing of space to third-party operators and new financing options. Ultimately, as the writers argue, DG will continue to grow in relevance for corporate investments because it can create opportunities for lower energy bills, tax credits, improved reliability, and product differentiation through environmentally conscious practices. 


\section{Technical Feasibility of Distributed Photovoltaics}

Gagnon et al. (2016) quantified the potential output of rooftop solar systems in the continental United States. The study employed rigorous geospatial data and statistical analysis to determine an upper bound of deployment, and estimated that energy generation based on the suitability of small, medium, and large buildings could meet $40 \%$ of total national electricity demand with a total technical potential of 1,119 gigawatts. The report thus established that individual systems with existing PV technology could, when aggregated, technically meet a significant portion of U.S. electricity demand. The researchers acknowledged, however, that integrating such a significant quantity of DPV would require a flexible grid and supporting infrastructure, the feasibility of which they did not determine.

Optimal Energy Inc. et al. (2014) detailed the efficiency in adopting renewable energy technologies in New York State. The study took account of many technologies, including biomass, hydro, wind, and solar, and how they might relate in the state's energy portfolio over the next 10 to 20 years. Considering solar in particular, the data used shows the amount of solar radiation hitting New York State as being more than 1,200 times the state's annual electricity consumption. However, due to obvious limitations such as space availability, technical efficiency, and saturation of solar on the grid, solar can provide only 13\% of New York State's electricity by 2030. Nevertheless, the researchers concluded that significant energy efficiency exists for solar given available technology during the study period and that pursuing this cost-effective clean energy could result in long-term net benefits for the state.

The U.K. OFGEM report (2007) was conducted by the British Office of Gas and Electricity Markets to address two long-term energy challenges: 1) reducing carbon dioxide emissions to tackle climate change and 2) securing clean and affordable energy to reduce dependence on imported fuel. To address carbon emission reduction, the researchers looked into the potential benefits of a decentralized energy supply. The study reviewed the key barriers to distributed generation, including cost, lack of information, complexities in the energy market, and regulatory barriers. The agency then concluded that distributed generation was an effective response to the energy challenges and recommended that the U.K. implement carbon pricing to increase the competitiveness of DG, which at the time accounted for only $10 \%$ of Britain's energy supply. 


\section{Existing Models of Cost Assessment}

The U.S. Department of Energy and the National Renewable Energy Laboratory created the System Advisor Model (SAM) to offer performance and financial models designed to facilitate decision-making for stakeholders in the renewable energy industry (Blair et al., 2014). It consists of a myriad of verified models that simulate electric power generation for grid-connected systems. Users create a SAM file by choosing the appropriate technology (PV, solar, wind, or biomass) and model which SAM will then auto-populate with default input variables that can be modified depending on location, equipment used, installation costs, financial incentives, and assumptions. Users can then run simulations based on these inputs and analyze the results.

As a continuation of NREL's benchmarking efforts, Fu et al. (2016) measured the installation costs of PV systems in the United States. The methodology was described as "bottom-up" accounting for all system costs incurred during installation of residential, commercial, and utility-scale systems, and has been used by state or regional agencies such as NYSERDA (Industrial Economics, 2017) to estimate costs specific to their territory. All costs were based on the national average sale price, meaning estimates would have included the profit margins of the installer or developer; these averages were then weighted by each state's installed capacity. Based on the study's results, costs for all three system types were shown to be on the decline when compared to other benchmarking reports since 2009; soft costs, however, which include permit acquisition, inspection, and installation labor, have been increasing. The installation costs of PV may therefore stagnate or even rise as hardware costs begin to plateau.

To determine the installation cost in dollars per watt, NYSERDA (Industrial Economics, 2017) estimated the balance-of-system costs (those not attributable to the PV panels, such as soft costs) of rooftop solar installations in New York State in 2016 and combined them with hard cost components determined in the NREL cost benchmark described above. The study separated cost estimates for residential and commercial systems by geographic area (Con Ed service territory, Long Island, and the rest of NY State). Data was collected from installers via a survey and cost estimates reflected the median weighted results according to the market share of respondents. Such data can thus be used as a relatively current cost estimate for installation in New York State and as a benchmark for assessing costs in the future. 
Brown et al. (2016) sought to develop a consistent method for estimating economic potential across renewable technologies, including wind, utility and distributed PV, hydro, geothermal, and bio. The first step in the model was to estimate technical potential; here the researchers estimated achievable energy generation capacity and annual generation using geospatial data, although the model did not consider future technology innovations that could increase this potential electricity output. The technical potential for DPV in particular was first estimated based on available roof space followed by an estimate of capacity based on assumed system sizes for "typical" roofs. The second step was estimating economic potential which for DPV was considered to be the utility bill savings that exceeded the capital cost of installation. The cost modeling also took into account the value of tax incentives as well as of $\mathrm{CO}_{2}$ emissions and health costs that were avoided. The results of the economic assessments, however, had not yet been published at the time of this writing. Nevertheless, the report provided a standard framework for assessing the technical and economic potential of DPV at a regional or national level. Future reports, by following the same system parameters and test cases, could also be benchmarked against this model.

\section{Regional Assessments of DPV Potential}

In quantifying the maximum technical potential of distributed PV on residential rooftops in Kailua Kona on Hawaii Island, Carl (2014) addressed three primary areas: 1) modeling solar radiation, 2) estimating rooftop area, and 3) calculating electricity potential from that solar radiation given the constraint of rooftop availability. The primary contribution of her study is a practical application of the variables required to calculate technical potential. Indeed, she used high resolution LiDAR data to estimate rooftop area and found that rooftop solar could provide $17 \%$ of the total electricity produced for the island, which, being subject to climate change and the nation's highest electricity rates, has made energy independence by 2030 a priority. Progressing toward such lofty goals, like those of many other regions, requires indepth study of solar potential. Carl's study, however, did not tie cost data to these estimates, and neither did it draw any conclusions about the economic impacts of significant solar installations.

Wiginton et al. (2010) applied geographic information systems and estimated system parameters to determine the technical potential of rooftop solar in southeastern Ontario. The study also broke ground by modeling the relationship 
between rooftop availability and population (70 $\mathrm{m}^{2} /$ capita) for use in regional policymaking. After calculating the available rooftop space, the researchers concluded that potential PV peak power capacity could be $157 \%$ of the region's peak power demand and meet $5 \%$ of total annual electricity demand. In response, therefore, to Ontario's renewable energy policies, this study aimed to offer deeper insight into the potential of rooftop solar in the hopes of facilitating financing schemes and formulating future policies. It provided a practical application of the variables needed to estimate the technical feasibility of rooftop solar at the regional level as well as a benchmark for cities at a similar latitude.

Romero-Hernandez et al. (2012) sought to understand the potential of solar in Mexico's northern border states; they wanted, in particular, to determine the economic sense of investing in it given the country's intense solar radiation. The researchers, however, reported difficulty in obtaining comprehensive data which led to much of the study being qualitative and having the following observation: many obstacles remain despite the evolving market for solar in Mexico. On the institutional level, the government had not set specific targets for solar capacity and tax incentives were insufficient. There was little understanding of the financial development and funding of solar projects. Manufacturers reported that the Mexican market lacks sufficient know-how or technology. Consumers did not understand the potential benefits and cost savings; they were less likely to accept a long-term view on the investment, particularly in rural communities. Nevertheless, the researchers argued that these obstacles were worth addressing because of the immense job creation that can come from investments in solar in addition to the environmental benefits. They used three models to estimate job creation as a function of dollars spent or megawatts installed. The study's conclusions thus reinforced the potential benefits-if related obstacles are addressed-of residential and large-scale solar power generation. They shed light on the many facets affecting the feasibility of solar as a power source.

Considering technical, economic, and legal perspectives, Johansson and Karlsson (2015) investigated the economic feasibility of solar in Swedish office buildings. They used a case study approach instead of performing a regional assessment, measuring data for five office buildings and analyzing the electricity load, appropriate system configurations, and electricity output for each. This data was then matched with economic conditions to test the profitability of each configuration. Results showed 
that investment in PV can be profitable given the right technical, economic, and legal conditions. The profitable system configurations determined in this study, which is somewhere between a full site and a regional assessment, could thus be assumed on a regional scale to estimate economic feasibility beyond a few properties.

Gerardi and Chin (2007) assessed the economic case for DG in Victoria, Australia. They considered all types of DG technologies, including solar, wind, and natural gas, along with two criteria: 1) "Is there a market failure which leads to an economically suboptimal level of distributed generation?", and 2) "Do the benefits of increasing the level of distributed generation through some market mechanism exceed the cost [of doing so]?" To respond to these questions, the researchers developed a model for the scope of DG using the following variables: capital cost of generation, fuel cost, operating cost, transmission losses, transmission costs, security of supply, and greenhouse gas emissions. Their study proved that while DG did not have the economies of scale that a centralized system enjoyed, it was advantageous within the Australian regulatory context because of carbon pricing. The predictions showed overall that electricity prices would drop by $5 \%$ and that emission of harmful gases would be substantially reduced.

Castillo et al. (2016) assessed the potential of solar power generation and created a suitability map of the European Union; in doing so, researchers applied multiple criteria to geographic data, including population distribution, topography, and proximity to the power grid. This methodology provided the variables needed for estimating suitability for solar on a regional scale. However, while the analysis was intended to facilitate fund allocation with a more accurate understanding of actual potential, no cost data were tied to the results.

\section{METHODOLOGY}

\section{Hypotheses}

The study tests two hypotheses:

Hypothesis 1: Distributed photovoltaics cannot fully meet the Bronx's energy demand without additional means of production. Based on the literature review, rooftop solar is not expected to meet all of the Bronx's energy demands. Brown et al. (2016), 
Optimal Energy Inc. et al. (2014), and Gerardi and Chin (2007) all discovered that solar can provide only a portion and never $100 \%$ of electricity needed. Energy from the sun, in addition, is intermittent and not easily stored (Brown et al., 2016). It is expected, therefore, that rooftop solar can provide a significant portion of electricity demanded and that other sources will be needed to meet the remainder.

Hypothesis 2: A system of distributed photovoltaics is economically feasible in the Bronx given existing government support programs and policies. U.K. OFGEM (2007), Sullivan et al. (2014), and World Economic Forum (2017) conclude that DPV technology is becoming less expensive and that utility bill savings can offset installation costs. Investing in installations can also have a positive net present value given that solar panels require little maintenance. All these studies, however, assume that existing government support programs will incentivize and defray costs. It is expected, therefore, that the same will hold true in the Bronx. Rooftop solar installations will thus be profitable investments given existing financial support from the government.

\section{Overview of Research Design}

To test these hypotheses, the research design analyzed three areas: resource, technical, and economic potential. This framework is a modified version of that employed by NREL (Brown et al., 2016) and is represented in Figure 2. Resource potential is the theoretical physical potential of the power source; in this case, it is how much power comes from the solar radiation hitting the Bronx. Technical potential builds on resource potential by taking into account given rooftop constraints and other system parameters to determine estimated system size and electricity output. Finally, economic potential refers to project implementation costs and savings from displaced electricity consumption. It helps determine whether or not savings exceed installation costs.

Economic potential can be defined in many ways; for this analysis, it is determined based on whether or not the value of electricity not consumed from the grid exceeds the capital cost of installing the PV system (Denholm, Margolis, Ong, \& Roberts, 2009).

The area under study is Bronx, N.Y. The sole utility provider for the area is Consolidated Edison, Inc., commonly known as Con Ed. This study does not focus 
on a specific sector and includes all buildings in the Bronx-residential, commercial, and industrial. It also does not consider the feasibility of DPV for New York City as a whole.

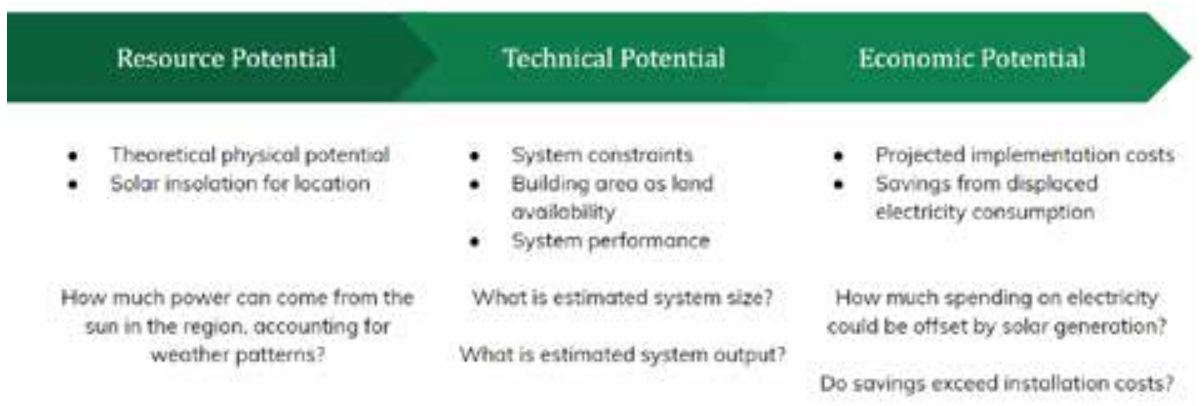

Figure 2: Overview of research design.

\section{Sources for the Model Design}

Based on the literature review, three existing sources were identified as drivers in designing the model used to analyze DPV potential in the Bronx. First, the NREL methodology (Brown et al., 2016) provided a general model for assessing technical and economic potential. It involved NREL's System Advisor Model (SAM) which accounts for weather patterns and system parameters to estimate power output (NREL, 2010). In addition, this study also uses the same test scenarios and standard system parameters employed by the NREL assessment.

Second, the NYSERDA balance-of-system study (Industrial Economics, 2017) provided the cost assessments that were collected from a survey of solar installers throughout New York State. That study reported baseline cost estimates of roofmounted solar systems for different customer segments-both residential and commercial-and geographic areas, including the Con Ed service territory. These baseline cost estimates, in turn, provided the cost per watt of installation that was used to estimate the capital cost of installing DPV in the Bronx.

Third, the methodology employed by Wiginton et al. (2010) was an applied model for regional assessment that provided the specific variables needed for thorough analysis. That study also focused on the technical potential of rooftop solar in Ontario, Canada which is at a similar latitude with the Bronx; this meant that methods for solar estimates could be shared. 


\section{Description of the Decision Support System}

Drawing on these three sources, a decision support system was designed for estimating the maximum system capacity, installation costs, electricity output, and savings of rooftop solar systems in the Bronx. It can be described in five parts as shown in Figure 3. First, it calculates the current system capacity that is needed to support the region. This can be used as a benchmark for comparing current and future states. Second, it estimates maximum energy production capacity given rooftop availability and NREL standards for system parameters. Third, the maximum system size combined with regional cost data and applicable government incentives determines the net cost of installation. Fourth, NREL's System Advisor Model estimates potential output by accounting for local weather patterns. Finally, savings from displaced energy are calculated using this estimated output. Economic feasibility is then determined by comparing savings and net installation costs over a multi-year basis.

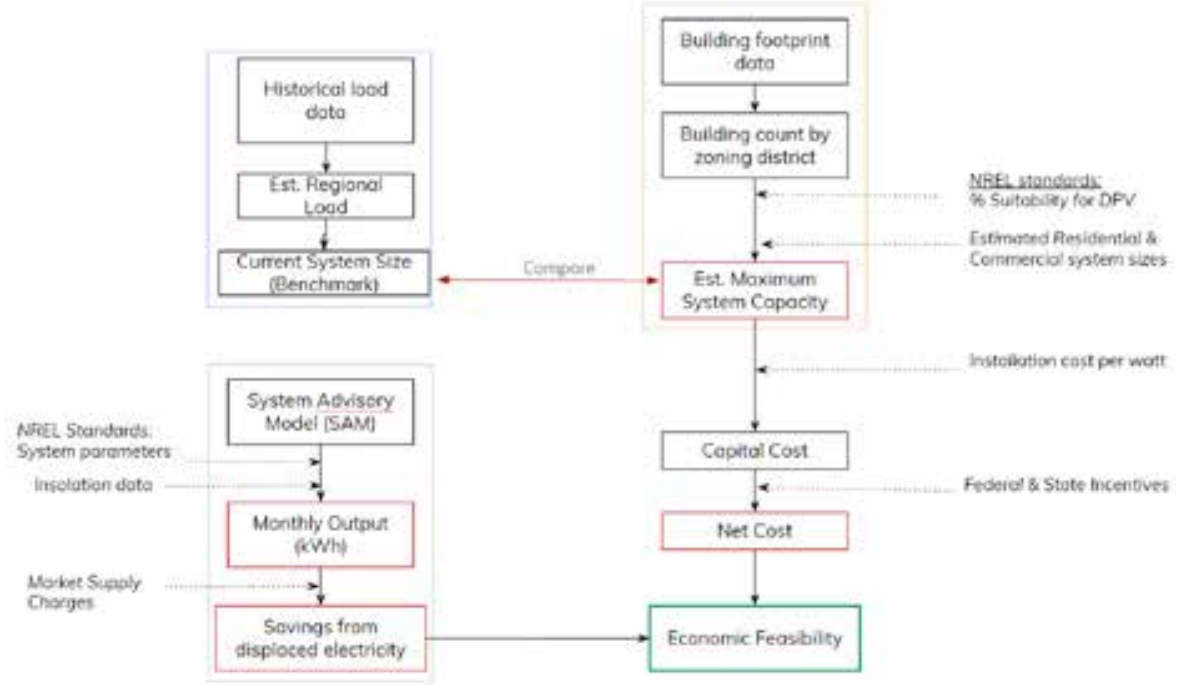

Figure 3: Decision support system design.

For this study, Bronx-specific data were used whenever these were available; estimates or values from other studies were utilized otherwise. The following subsections detail the specific factors in the decision support system and how the data were applied for the Bronx case study. 
Current System Size. Load is the electricity use by end-users or customers as measured in MW (NY ISO, n.d.). The current system size is thus determined by historical load demand. This estimated load, in turn, can be used as a benchmark to compare the size of the current power system to that proposed in this study.

For the Bronx case study, current load for the Con Ed region was calculated from NY ISO's metrics of monthly wattage as generated by Con Ed (NY ISO, n.d.). The percentage of electricity supplied to the Bronx was then assumed to be based on the percentage of the population. According to the U.S. Census Bureau, the total population of the area which Con Ed services-New York City and Westchester County-was 9.5 million in 2017, with $15.3 \%$ or 1.4 million living in the Bronx. It is thus assumed that the Bronx requires an equivalent percent of the total load supplied by Con Ed.

Technical Feasibility: Maximum Solar Capacity. The technical feasibility of roof-mounted solar depends on rooftop availability. Due to scope, time, and resource constraints of this research and model, however, exact calculations of rooftop space could not be determined. Thus, for the purposes of this research, the building footprint was considered to be equivalent to rooftop area (other studies related to roof-mounted technologies, including Ackerman et al. [2012], have used this method). In accordance with standard NREL scenarios, it was assumed that buildings with a footprint of 100-5000 square feet could accommodate residentialgrade systems while buildings with a footprint greater than 5000 square feet could accommodate commercial-grade installations (Brown et al., 2016). Residential systems average $8 \mathrm{~kW}$ in size (Brown et al., 2016) while commercial ones range from 36 to $170 \mathrm{~kW}$ in size since these systems apply to any building with a footprint greater than 5000 square feet (EIA, n.d.).

The amount of rooftop area for the Bronx was determined based on the NYC Department of Buildings shapefile of buildings greater than 400 square feet. The percentage of rooftop availability was therefore assumed to be $80 \%$ for residential and 50\% for commercial buildings (Brown et al., 2016; EIA, n.d.). Furthermore, systems of $36 \mathrm{~kW}$ were assumed for all commercial buildings because buildings in the Bronx skew toward smaller areas. 
Combining rooftop availability, the number of buildings available for rooftop solar, and system sizes for each building determines maximum system capacity. This value can then be applied to estimate electricity output and installation costs.

Technical Feasibility: Annual Electricity Output (kWh). Output from solar panels varies depending on location and time of year due to the intermittent nature of sunlight. A critical aspect, therefore, of the technical potential of DPV is solar insolation specific to the area of study. Thus, NREL's System Advisor Model, which calculates annual output from previously determined system capacity, uses computer models developed at NREL, Sandia National Laboratories, the University of Wisconsin, and other organizations (NREL, 2010) to represent the performance of renewable energy projects, models that require weather data and performance characteristics of physical equipment as inputs.

Weather data was imported from NREL's National Solar Radiation Database (NSRDB). Based on location latitude and longitude, the NSRDB is a serially complete collection of half-hourly values of meteorological data and the three most common measurements of solar radiation-global horizontal, direct normal, and diffuse horizontal irradiance.

Performance characteristics of physical equipment were kept consistent with those employed by the NREL analysis. Panels were assumed to have a DC to AC ratio of 1.2 , an inverter efficiency of $96 \%$, and a loss of 14\% (Brown et al., 2016). These technical parameters, however, can be adjusted to analyze different system types or technological improvements.

With these inputs, SAM calculated the monthly and annual total system output in $\mathrm{kWh}$. This was used to determine the value of electricity not consumed from the grid and the percentage of Bronx electricity demand that can be met with DPV.

Economic Feasibility: Capital Cost of Installation. The cost of installation is dependent on the system size as determined by rooftop availability and standard system parameters; this model specifically considers the cost per watt of installation, a standard measure used by NREL and NYSERDA. Table 1 details the cost breakdown for each system type. In accordance with the methodology employed at NREL, operation and maintenance costs are considered to be 0 . Very little maintenance is 
required once the panels are installed, and most of them are covered by a 20-year warranty in the event of damage (Brown et al., 2016).

\begin{tabular}{|c|c|c|c|c|c|c|c|}
\hline & \multirow[b]{2}{*}{ Line Hem } & \multicolumn{6}{|c|}{ Roof-mousted } \\
\hline & & \multicolumn{2}{|c|}{ Residential } & \multirow{2}{*}{$\begin{array}{r}\text { \%en trotal } \\
18 \% 6\end{array}$} & \multicolumn{2}{|c|}{ Commerrial } & Se of total \\
\hline \multirow{4}{*}{ है है है } & Mosale & $\mathbf{s}$ & 0.64 & & 5 & 0.64 & $20 \% 6$ \\
\hline & Inverter & $\$$ & 0.21 & 695 & s & 0.13 & $6 \%$ \\
\hline & Strusearal BOS & s & 0.12 & 35 & 5 & 0.17 & $8 \%$ \\
\hline & Flectrical poos & 5 & 0.25 & $7 \%$ & 5 & 0.16 & $7 \%$ \\
\hline \multirow{7}{*}{$\begin{array}{l}\frac{H}{8} \\
\text { 总 }\end{array}$} & Permintag, Zenieg. Inspection & 5 & 0.24 & $7 \%$ & $\$$ & 0.06 & 346 \\
\hline & Permis Foe & $\$$ & 0.05 & $1 \%$ & $\$$ & - & $0 \%$; \\
\hline & Intercounection & 5 & 0.05 & $15 \mathrm{n}$ & 5 & 0,02 & $19 \mathrm{~m}$ \\
\hline & Installatice Labor & $\$$ & 0.39 & $11 \%$ & $\$$ & 0,42 & $19 \%$ \\
\hline & Custemer Acepaisition & $\$$ & 0.50 & 1496 & $\$$ & - & - \\
\hline & Predevelogment Crigination & s & - & $n_{n}$ & s & 0.26 & $124 \mathrm{~m}$ \\
\hline & Design \& Enpiasering & & - & 986 & 5 & 0.03 & $1 \%$ \\
\hline \multirow{9}{*}{$\frac{\sqrt{3}}{\frac{1}{8}}$} & Supply Chain / Logisties & 5 & 0.27 & $7 \% 6$ & 5 & $=$ & + \\
\hline & Sades Tax & $\mathbf{s}$ & - & - & $\mathbf{s}$ & 0.04 & $2 \%:$ \\
\hline & Coutingency & s & $=$ & $=$ & s & 0.06 & 34. \\
\hline & Overtuead & s & 0.47 & 1356 & s & 0.19 & $90 \%$ \\
\hline & Profit & 5 & 0.42 & 1286 & s & 0.04 & 24 \\
\hline & Total Costs & 5 & 3.61 & 10048 & s & 2.22 & 10048 \\
\hline & Subiotal: Handware costs & \$ & 1.22 & & s & 1.10 & \\
\hline & Subtotal: Soft Costs & $\$$ & 1.23 & & s & 0.79 & \\
\hline & Subtotal: Other BOS Flements & 5 & 1.16 & & 5 & 0.33 & \\
\hline
\end{tabular}

Table 1: Balance-of-system costs—Con Ed service territory (2017).

Data source: NYSERDA (Industrial Economics, 2017).

The cost per watt of installation for the Bronx was $\$ 3.61$ for residential and $\$ 2.22$ for commercial systems. These values were based on NYSERDA (Industrial Economics, 2017) and the survey results of Con Ed service territory installers. Installation cost estimates included hardware and material costs, soft costs, and other balance-of-system cost elements.

Installation costs can also be offset by federal and state incentives, the value of which can be adjusted to reflect policies and programs applicable to the region of study. Incentives are offered in many forms, including rebates, tax exemptions, and grants, and specify eligible technologies, regions, and system sizes (NSRDB, 2018).

Solar installations in the Bronx can be eligible for Investment Tax Credit (ITC) and the NY-Sun Incentive Program. The federally-sponsored ITC applies to solar technologies, has no financial limit, and covers a maximum system size of $100 \mathrm{~kW}$. 
This means that each individual rooftop system considered in this study, being less than $100 \mathrm{~kW}$ in size, qualifies for ITC. As of 2018 , the ITC was valued at $30 \%$ of the installation cost but will decline to $10 \%$ by 2022 and expire in 2023 (U.S. Department of Energy, n.d.).

The second government incentive applied in this model is the NY-Sun Incentive Program which is sponsored by NYSERDA at the state level. These grants apply to grid-connected photovoltaics-making the systems considered for this study eligible-and are valued based on wattage installed. For the Con Ed service territory, the incentive is $\$ 0.40 /$ watt and expires in 2023 (U.S. Department of Energy, n.d.).

The ITC and NY-Sun incentives were applied in this model because of regional and technical eligibility. The total cost of installation, however, will be allocated over a number of years given the impossibility of installing maximum potential capacity all at once. Thus, for this study, estimates for one (as a benchmark), ten, and 20 years will be conducted. Doing so will better reflect the impact of inflation and changing incentive values.

The total cost of solar technologies, however, has plateaued despite declining hardware costs. Soft costs, in fact, have increased in some cases. These trends are shown in Figure 4. Further cost reductions, therefore, were no longer considered for this analysis, although the system does allow changes to these parameters for further modeling.

Economic Feasibility: Value of Electricity Not Consumed from the Grid. Electricity is not free even after rooftop solar systems are installed; fixed demand charges still remain given that the system analyzed in this study relies on grid infrastructure (CUNY, n.d.). DPV could be economically feasible then if the value of offset electricity, multiplied by the amount of kilowatt hours produced annually by the system, exceeds the capital cost of installation as calculated above.

For the Bronx case study, Con Ed's 2016 Annual Report expressed variable supply charges that could be offset by $37 \%$ or 8 cents/kWh for properties with rooftop solar installations. 


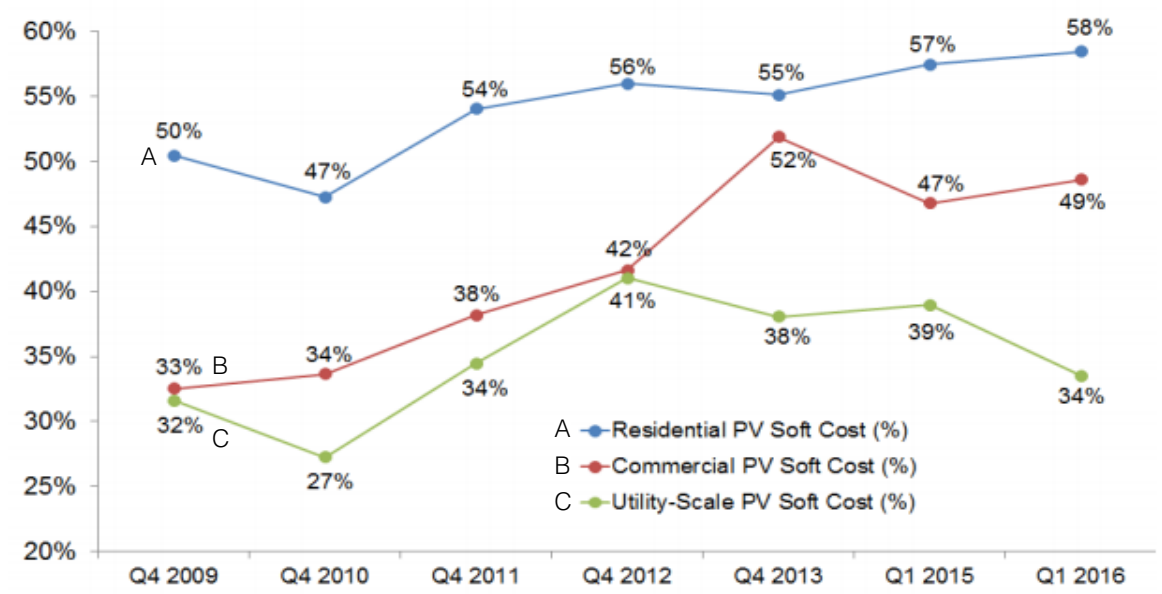

Figure 4: Trends in soft costs as a percentage of total cost for solar installations (2009-2016). Data source: Fu et al. (2016).

\section{RESULTS AND DISCUSSION}

The methodology described above was applied specifically to rooftop solar systems in Bronx, NY. The model relied on readily available data and on some assumptions that were consistent with NREL and NYSERDA studies. The results were divided into two stages: technical and economic potential. Technical potential involves the estimated maximum system capacity and annual electricity output. Those in turn drive the economic potential, which involves installation costs and accounting for financial incentives and electricity cost savings.

\section{Technical Feasibility}

Based on calculated rooftop availability and system parameters, rooftops in the Bronx can accommodate 748 megawatts of potential solar power production capacity. System size estimates were then applied to the System Advisor Model (SAM) as described above to determine electricity output, which itself depends on Bronx weather patterns, solar power's dependence on sunlight hours, system capacity, and technical parameters such as inverter efficiency. Annual output was thus estimated at 955 million kWh. Figure 5 shows monthly output, which varies greatly due to 
weather patterns and solar radiation intensity. The maximum amount of electricity produced by the maximum installed solar capacity would be only $11 \%$ of annual electricity consumption in the Bronx (Con Ed, n.d.).

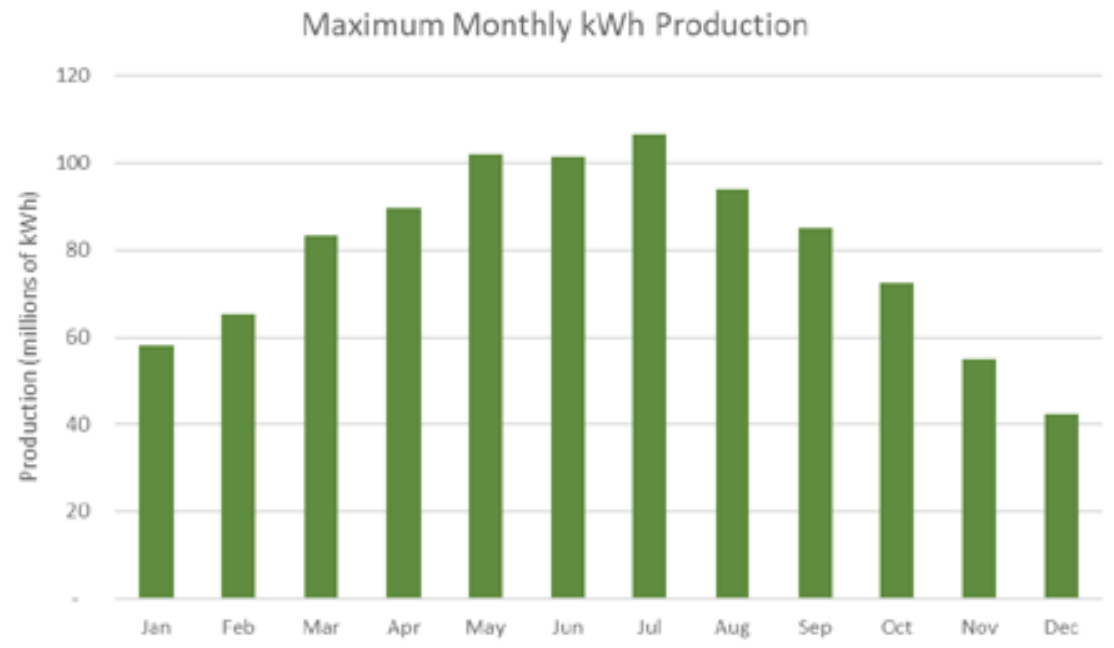

Figure 5: Monthly output from solar panels (kWh).

The space needed to support $750 \mathrm{MW}$ of rooftop solar is also significant-panels would cover $16 \mathrm{~km}^{2}$ while providing for only a small percentage of the Bronx's electricity needs. If solar was to provide all of the Bronx's electricity, panels would take up approximately $200 \mathrm{~km}^{2}$. Thus, while a capacity of $750 \mathrm{MW}$ is possible given current rooftop space and assumptions of availability, concerns with scale and space commitment cannot be discounted.

Nevertheless, rooftop solar could have capacity that is comparable to existing power sources even though electricity generation is intermittent. Compared, for instance, to monthly wattage generated by Con Edison (NY ISO, n.d.), the capacity from solar was at least $67 \%$ of system requirements for July and $94 \%$ at most in April. Indeed, the total capacity provided by rooftop solar remains the same despite seasonal fluctuations in capacity demand (this relationship is shown in Figure 6). The Bronx, for instance, requires approximately 900MW on average, with demand peaking at $2000 \mathrm{MW}$ during a heat wave in July of 2013 as reported by Con Ed (Con Ed, 2017). The maximum capacity from rooftop solar, therefore, is comparable with what is required to support electricity consumption. 


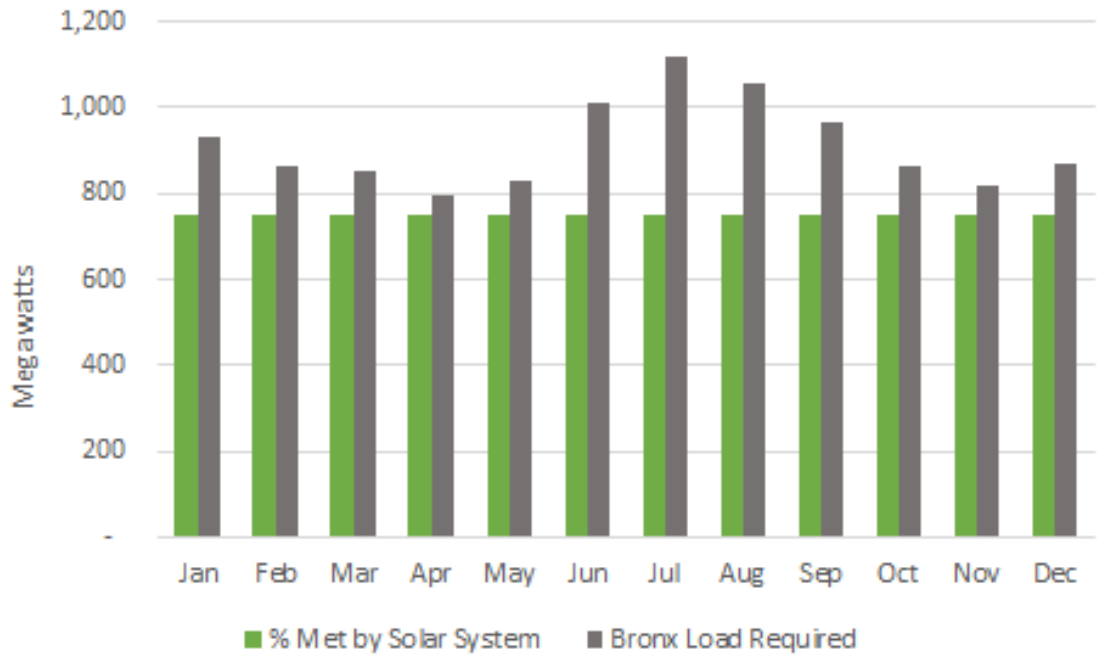

Figure 6: Maximum system capacity compared to capacity required monthly.

\section{Economic Feasibility}

As described in the methodology outlined above, estimated system capacity drives installation cost and estimated output drives electricity cost savings. Three scenarios were thus conducted to determine these costs: Scenario 1) implementation in one year, Scenario 2) implementation in ten years, and Scenario 3) implementation in 20 years. Each scenario begins in 2019 and accounts for installation costs, inflation, schedule of tax incentives, and annual cost savings. Table 2 details each scenario across three alternatives: with the current incentive schedule, without incentives, and if incentives continued at 2019 rates.

Scenario 1: Implementation in one year serves as a benchmark for the time value of money and the impact of delaying installation. Installation costs are estimated at $\$ 1.55$ billion with a payback period of 20 years.

Scenario 2: Implementation over ten years would cost $\$ 2.46$ billion and have a payback period of 37 years under the assumption that $10 \%$ of the maximum capacity is installed each year. Figure 7 shows the capital cost, net cost after incentives, and annual savings for this scenario. The net cost of installation is approximately $40 \%$ less than the capital cost until 2023 which is when both the ITC and NY-Sun 
incentives are set to expire. Annual savings continue to increase as both system size and output do the same; these savings will continue at approximately $\$ 75$ million after the maximum of $750 \mathrm{MW}$ is installed by year ten and outweigh installation costs by year 37. Without these government incentives, payback would not occur until year 43; conversely, payback would occur within 28 years if government incentives maintained 2019 rates.

\begin{tabular}{|l|c|c|c|}
\hline & Scenario 1 & Scenario 2 & Scenario 3 \\
\hline Length of Implementation & 1 year & 10 years & 20 years \\
\hline Government incentives as scheduled in 2019 & \\
\hline Total Install Cost & \$1.55 billion & \$2.46 billion & \$2.92 billion \\
\hline Payback Period & 20 years & 37 years & 46 years \\
\hline Without any government incentives & \$2.65 billion & $\$ 2.87$ billion & \$3.15 billion \\
\hline Total Install Cost & 35 years & 43 years & 49 years \\
\hline Payback Period & \$1.55 billion & $\$ 1.71$ billion & \$1.91 billion \\
\hline Government incentives continuing at 2019 rates & 28 years & 33 years \\
\hline Total Install Cost & 20 years &
\end{tabular}

Table 2: Economic feasibility-3 scenarios.

Scenario 3: Implementation over 20 years would cost $\$ 2.96$ billion and have a payback period of 46 years. This scenario assumes that $5 \%$ of the maximum system size is installed each year. Figure 8 shows the capital cost, net cost after incentives, and annual savings for this scenario. As with Scenario 2, installation costs are offset by government incentives until 2023. The value of incentives per year is lower, however, since it is dependent on watts installed. This scenario also has a longer payback period because it takes twice as long to install the full system and reach maximum savings potential. Without government incentives, payback would not occur until year 49; if government incentives maintained 2019 rates, payback would occur within 33 years. 


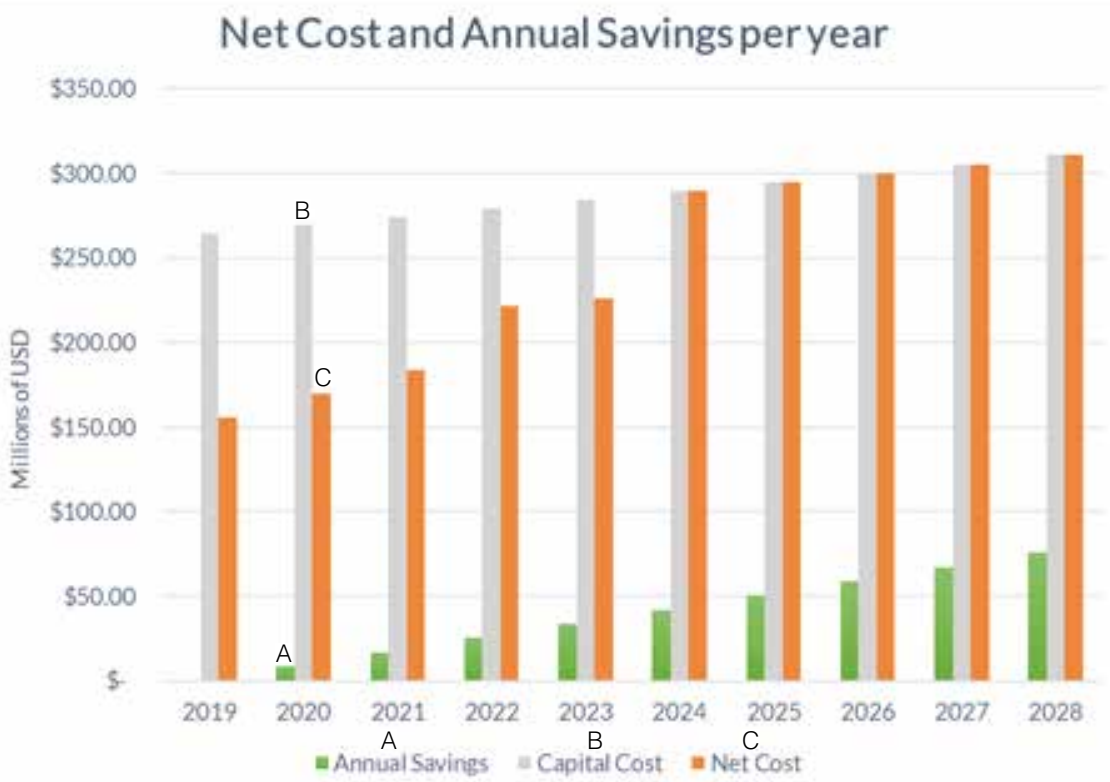

Figure 7: Scenario 2-10-year implementation.

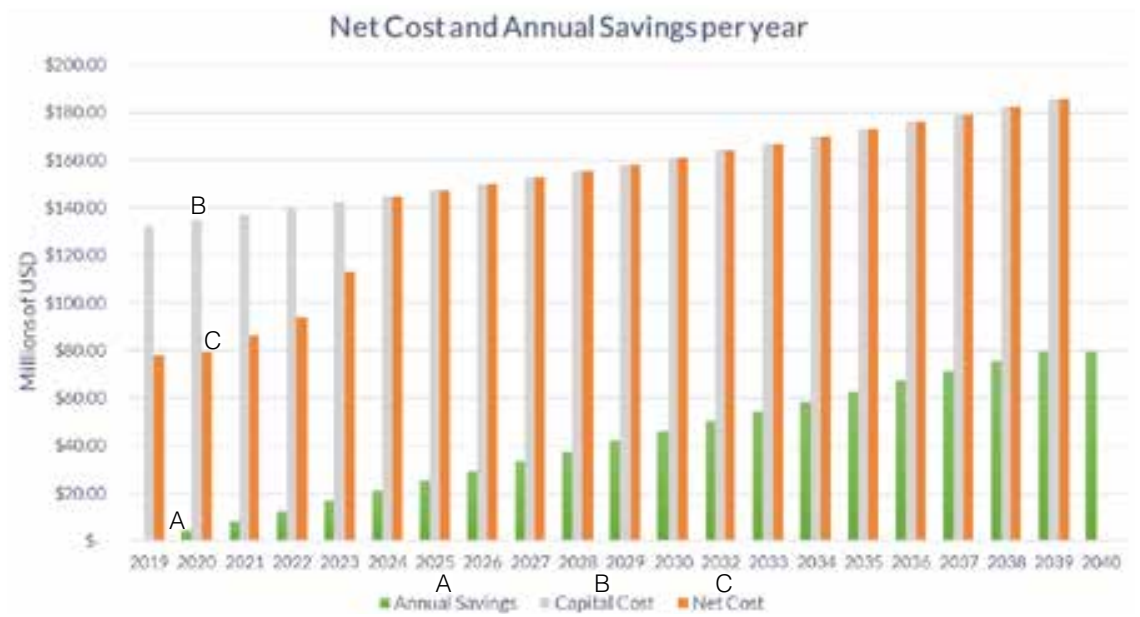

Figure 8: Scenario 3-20-year implementation. 
All three scenarios will be profitable eventually. Economic feasibility thus depends on acceptance criteria. To tie these results to the two hypotheses posed:

Hypothesis 1: Distributed photovoltaics cannot fully meet the Bronx's energy demand without additional means of production. This hypothesis was proven to be truerooftop solar could only meet $11 \%$ of Bronx electricity demand even with the maximum system size possible. Additional power sources would be required given the intermittency of solar power supply and the amount of electricity consumed in the Bronx.

Hypothesis 2: A system of distributed photovoltaics is economically feasible in the Bronx given existing government support programs and policies. The truth of this hypothesis is dependent on acceptance criteria. All three scenarios will be profitable eventually, when costs of electricity not consumed from the grid outweigh installation costs. Payback is possible even with the expiration of existing government support programs by 2023. Extending support programs, however, could shorten the payback period. The nuances and recommendations for improving economic feasibility are discussed below.

\section{Discussion}

Developing and maintaining a sustainable energy system is one of our biggest challenges (World Economic Forum, 2017). Yet the importance of renewable energies for reducing greenhouse gas emissions and securing power diversification cannot be ignored (Pérez-Arriaga et al., 2016). This study sought to contribute to our understanding of solar technology and its many facets-technical, economic, and environmental.

This study developed a decision support system for DPV on a regional level which was applied to the Bronx as a practical case. Using the system, it was determined that rooftop solar could not fully meet the Bronx's electricity demand yet could factor into a more diversified energy portfolio that leverages the benefits of DG and renewables. Indeed, the system calculated that rooftop solar could provide for $11 \%$ of the Bronx's electricity needs, a level comparable to national estimates in Brown et al. (2016) and state estimates in Optimal Energy Inc. et al. (2014). It is important to recognize, however, that other factors beyond those captured by currently available data could be critical in the installation and operation of rooftop solar. 
One such factor is consumer psychology. DG relies on individuals to be the decision makers and adopt this technology, yet this system bases estimates on factors like availability of space and cannot capture property owner intention given the data available. It is still unclear whether or not property owners would be willing to invest in solar even with the prospect of saving on electricity bills. This may be a major obstacle in areas occupied primarily by renters-in the Bronx alone, only $20 \%$ of homes are owner-occupied and renters pay the electric bills (U.S. Census Bureau, n.d.). Indeed, the annual growth rate of installed rooftop solar capacity has declined in New York State (CUNY, n.d.; see Figure 9). This may indicate that the wave of early adopters has already passed. Incentive programs must continue, then, if regions deem rooftop solar to be critical for their future energy systems.

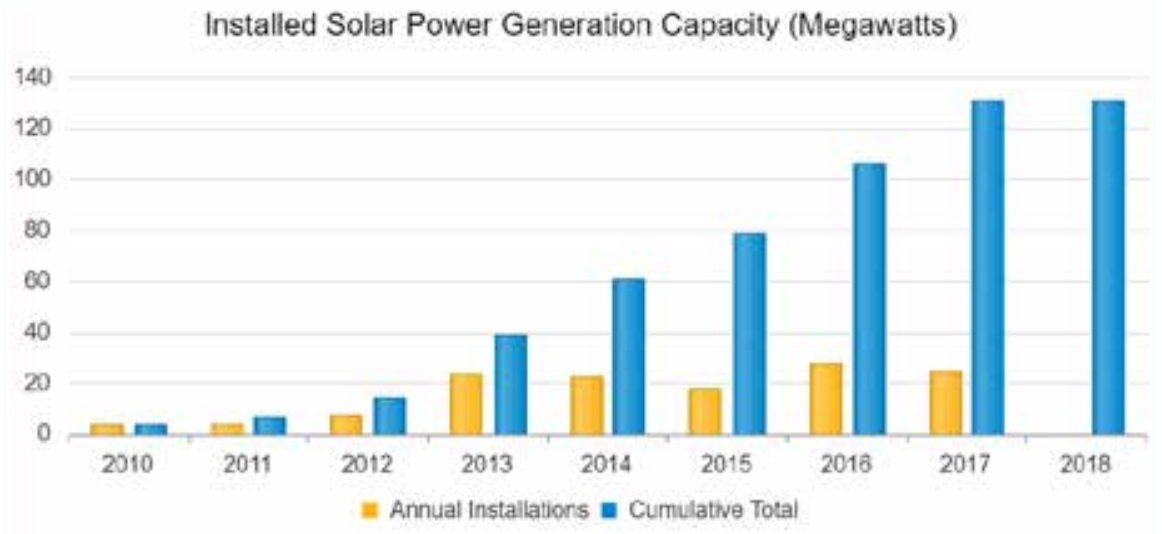

Figure 9: Installed solar power generation capacity in the Bronx (2010-2018). Data source: NY Solar Map (CUNY, n.d.).

Another factor is government support and related policies. The solar industry has been growing since the early 2000s due in part to government support programs that defray cost and incentivize installers (SEIA, n.d.). As shown in this study, current state and federal incentives can decrease installation costs by $40 \%$ in the Bronx. These programs, however, will expire after 2023, potentially making solar a negative investment by that time. To encourage more solar installations, policymakers have two options: they can either extend the support programs or implement a carbon tax. A carbon tax increases the financial cost of emissions for the user by imposing a \$/ton tax on greenhouse gas emissions (Morris, 2013). Installing DPV and offsetting 
fossil fuel consumption can negate this cost; indeed, Gerardi and Chin (2007) and Pérez-Arriaga et al. (2016) determined that DG can be economical if it is used to avoid or reduce a carbon tax. The United States currently does not impose a carbon tax but 40 other countries do (World Bank Group, 2016). Implementing a carbon tax, therefore, is one market instrument for incentivizing solar installers and potentially decreasing our carbon footprint at little public cost.

A third factor is limited understanding of the grid's ability to accommodate DG. As expressed in Gagnon et al. (2016), Optimal Energy Inc. et al. (2014), and U.K. OFGEM (2007), a significant quantity of rooftop solar requires a flexible grid and technically supportive infrastructure to operate. The cost of implementation would increase should technical upgrades be required, thereby decreasing feasibility. Upgrading infrastructure to support modern energy demands, however, may be inevitable given that the majority of grid infrastructure pre-dates the 1980s (Industrial Economics, 2017). Future research is thus necessary to determine how effective the current grid is at integrating DPV.

The proposed decision support system, while offering insight into the technical and economic feasibility of DPV, is not a comprehensive life cycle assessment or sustainability impact tool. Additional factors such as net carbon displacement and ecological impact can be included in future versions given that standard metrics are available. As such, even though solar technologies can reduce carbon emissions in comparison with fossil fuels, decision-makers ought to consider the sustainability trade-offs and identify the best renewables for their regions while factoring in weather patterns, resource availability, and end-of-life management concerns.

There is currently little formal or public reporting on existing installations in dense urban environments that can provide insight into qualitative factors. Our recommendation, then, for future study is a case study of a series of installations in the Bronx. One existing development is located at Hunts Point, the largest installation in New York City (Scarborough, 2014). In fact, additional plans to increase installed capacity on multi use buildings nearby have already been approved by the state (Level, 2016). Actual inputs and outputs can thus be measured given that these systems will be islanded together. Researchers will be able to observe the impact of private landownership, existing grid infrastructure, technical efficiency, and regulation. Having more of such detailed actual data from the Bronx would then enable an extension of the model designed in this study, refining its accuracy 
and insights. Ultimately, we can encourage market participation and accelerate integration of renewables into our energy system by taking this research into practical applications and determining investment opportunities, such as rooftop solar in the Bronx.
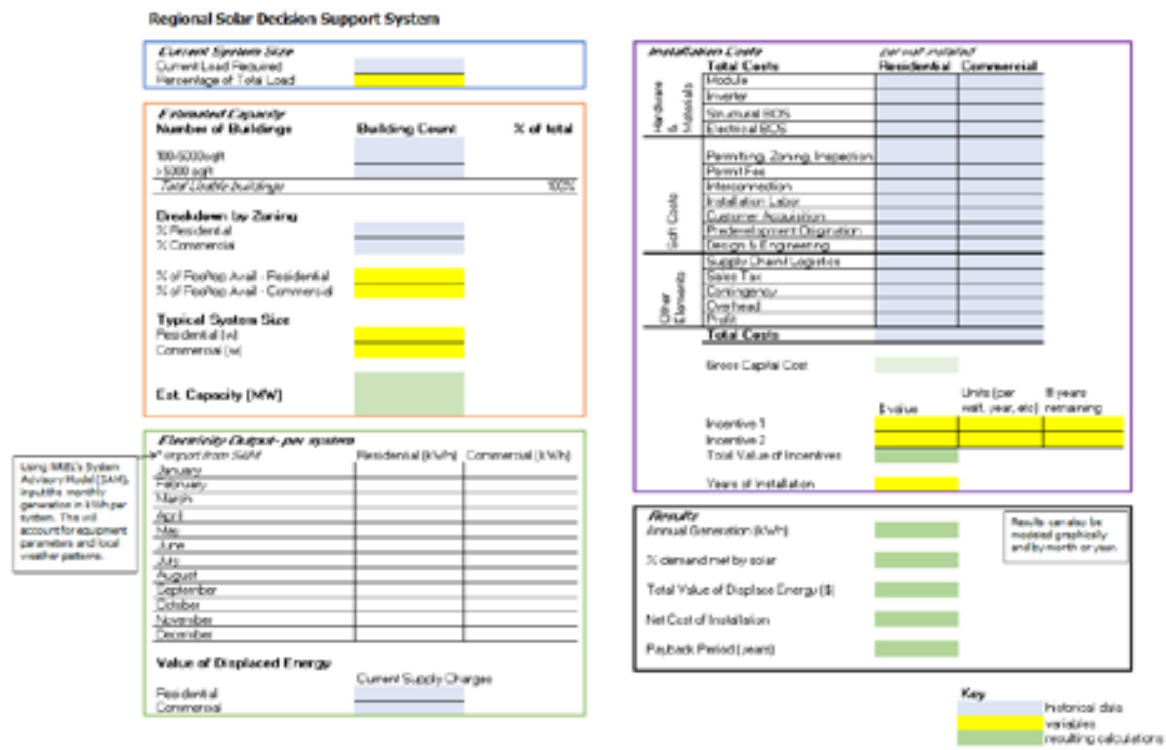

Figure 10: Screenshot of decision support system UI (user interface).

\section{CONCLUDING REMARKS}

A core thesis of this research study is that the promotion of sustainability and social innovation requires the design of systems that help policymakers and other stakeholders make informed, if not optimal, decisions. This research thus aims to contribute toward a more sustainable world (Stoner, 2013) by proposing and designing a decision support system that uses clear metrics and equations to determine the technical and economic feasibility of rooftop solar power generation in Bronx, NY. The model was designed by building on existing models used for regional assessment.

We also provided a deeper discussion of related issues as feasibility is a complex topic. Thus, while this study was able to estimate electricity generation and costs of rooftop solar, further research in this area is needed. In fact, the results of this study 
make the case for deeper analysis of rooftop solar installations given that estimates show potential for offsetting fossil fuels and reducing electricity costs. We therefore propose that additional specific metrics can be applied to extend the model and improve its accuracy by tracking an existing case such as the Hunts Point site.

Lastly, we hope that other researchers may use our work as a starting point for designing decision support systems for solar energy in other cities or regions around the globe, thereby contributing toward a more sustainable world.

\section{REFERENCES}

Ackerman, K., Plunz, R., Conard, M., Katz, R., Dahlgren, E., \& Culligan, P. 2012. The potential for urban agriculture in New York City: Growing capacity, food security, \& green infrastructure. New York: Columbia University. Available at urbandesignlab.columbia.edu/files/2015/04/4_urban_agriculture_nyc.pdf.

Blair, N., Dobos, A., Freeman, J., Neises, T., Wagner, M., Ferguson, T., Gilman, P., \& Janzou, S. 2014. System Advisor Model, SAM 2014.1.14: General description. NREL/TP-6A20-61019. Golden, CO: National Renewable Energy Laboratory. Available at www.nrel.gov/docs/fy14osti/61019.pdf.

Brown, A., Beiter, P., Heimiller, D., Davidson, C., Denholm, P., Melius, J., Lopez, A., Hettinger, D., Mulcahy, D., \& Porro, G. 2016. Estimating renewable energy economic potential in the United States: Methodology and initial results. NREL/TP-6A20-64503. Golden, CO: National Renewable Energy Laboratory.

Carl, C. 2014. Calculating solar photovoltaic potential on residential rooftops in Kailua Kona, Hawaii. Los Angeles: University of Southern California. Available at https://spatial.usc.edu/wp-content/uploads/2014/03/CarlCarolineThesis.pdf.

Castillo, C. P., Batista e Silva, F., \& Lavalle, C. 2016. An assessment of the regional potential for solar power generation in EU-28. Energy Policy, 88: 86-99.

Con Ed. n.d. Service territory. Available at https://www.coned.com/en/businesspartners/service-territories. 
Con Ed. 2017. 2016 annual report. Available at investor.conedison.com/phoenix. zhtml?c=61493\&p=irol-reportsannual.

CUNY [City University of New York]. n.d. NY solar map. New York: City University of New York. Available at nysolarmap.com.

Denholm, P., Margolis, R., Ong, S., \& Roberts, B. 2009. Break-even cost for residential photovoltaics in the United States: Key drivers and sensitivities. NREL/TP6A2-46909. Golden, CO: National Renewable Energy Laboratory.

EcoMen Solar. 2016. Reasons solar should be front and center in your financial performance discussions. Freehold, NJ: EcoMen Solar, LLC. Available at ecomensolar.com/nyc-commercial-incentives.

EIA [U.S. Energy Information Administration]. n.d. Commercial buildings energy consumption survey. Washington, DC: U.S. Energy Information Administration. Available at www.eia.gov/consumption/commercial.

EPA [U.S. Environmental Protection Agency]. n.d. Centralized generation of electricity and its impacts on the environment. Washington, DC: U.S. Environmental Protection Agency. Available at www.epa.gov/energy/centralizedgeneration-electricity-and-its-impacts-environment.

Farrell, J. 2011. Why we should democratize the electricity system. Grist. Available at https://ilsr.org/wp-content/uploads/files/democratizing-electricity-system.pdf.

Fu, R., Chung, D., Lowder, T., Feldman, D., Ardani, K., \& Margolis, R. 2016. U.S. solar photovoltaic system cost benchmark: Q1 2016. NREL/TP-6A20-66532. Golden, CO: National Renewable Energy Laboratory. Available at www.nrel.gov/ docs/fy16osti/66532.pdf.

Gagnon, P., Margolis, R., Melius, J., Phillips, C., \& Elmore, R. 2016. Rooftop solar photovoltaic technical potential in the United States: A detailed assessment. NREL/TP-6A20-65298. Golden, CO: National Renewable Energy Laboratory. Available at https://www.nrel.gov/docs/fy16osti/65298.pdf. 
Gerardi, W., \& Chin, L. 2007. Understanding the business case for distributed energy generation in Victoria. Melbourne: McLennan Magasanik Associates.

Industrial Economics, Incorporated. 2017. Solar balance-of-system costs baseline cost study. Albany, NY: New York State Energy Research and Development Authority. Available at www.nyserda.ny.gov/-/media/Files/Publications/PPSER/ Program-Evaluation/2017ContractorReports/Solar-Balance-of-System-CostBaseline-Study.pdf.

Johansson, N., \& Karlsson, J. 2015. Economic feasibility for solar PV in Swedish office buildings: A case study approach. Göteborg, Sweden: Chalmers University of Technology. Available at http://publications.lib.chalmers.se/ records/fulltext/225563/225563.pdf.

Level. 2016. Hunts Point microgrid: NY prize stage 1 feasibility study. NYSERDA Agreement \#64712. Available at https://www.nyserda.ny.gov/-/media/NYPrize/ files/studies/15-Hunts-Point.pdf.

McGeehan, P. 2017. Cuomo confirms deal to close Indian Point nuclear plant. The New York Times, January 9. Available at https://www.nytimes. com/2017/01/09/nyregion/cuomo-indian-point-nuclear-plant.html.

Morris, A. 2013. The many benefits of a carbon tax. The Brookings Institution, February 26. Available at www.brookings.edu/research/the-many-benefits-ofa-carbon-tax.

NREL [National Renewable Energy Laboratory]. 2010. System Advisor Model (SAM). Golden, CO: National Renewable Energy Laboratory. Available at sam.nrel.gov.

NSRDB [National Solar Radiation Database]. 2018. What is the NSRDB? Golden, CO: National Renewable Energy Laboratory. Available at nsrdb.nrel.gov/background.

NY ISO [New York Independent System Operator]. n.d. Load data. Available at https://www.nyiso.com/load-data.

Optimal Energy Inc., American Council for an Energy-Efficiency Economy, \& Vermont Energy Investment Corporation. 2014. Energy efficiency and 
renewable energy potential study of New York State. Albany, NY: New York State Energy Research and Development Authority. Available at https://www.nyserda. ny.gov/About/Publications/EA-Reports-and-Studies/EERE-Potential-Studies.

Pérez-Arriaga, I., Knittel, C., et al. 2016. Utility of the future: An MIT energy initiative response to an industry in transition. Cambridge, MA: MIT Energy Initiative. Available at http://energy.mit.edu/wp-content/uploads/2016/12/ Utility-of-the-Future-Full-Report.pdf.

Romero-Hernandez, S., Rodríguez-Granada, B., Romero-Hernandez, O., \& Wood, D. 2012. Solar energy potential in Mexico's northern border states. Washington, DC: Woodrow Wilson International Center for Scholars. Available at https:// www.wilsoncenter.org/sites/default/files/Border_Solar_Romero.pdf.

Scarborough, J. 2014. Hunts Point home to largest solar panel installation in NYC. New York Daily News, February 25. Available at https://www.nydailynews. com/new-york/bronx/hunts-point-home-largest-solar-panel-installation-nycarticle-1.1700460.

SEIA [Solar Energy Industries Association]. n.d. Solar investment tax credit (ITC). Washington, DC: Solar Energy Industries Association. Available at www.seia. org/initiatives/solar-investment-tax-credit-itc.

Stoner, J. A. F. 2013. What we want this journal to be. Journal of Management for Global Sustainability, 1(1): 1-6.

Sullivan, J. E., Cannon, G., Burton, D., Johnson, S., \& White, J. 2014. Why end users are investing (big) in distributed generation. The Electricity Journal, 27(2): 23-32.

U.K. OFGEM [Office of Gas and Electricity Markets]. 2007. Review of distributed generation. London/Glasgow/Cardiff: Office of Gas and Electricity Markets. Available at https://www.ofgem.gov.uk/ofgem-publications/52326/reviewdistributed-generation.pdf. 
U.S. Census Bureau. n.d. Bronx County (Bronx Borough), New York. Washington, DC: U.S. Census Bureau. Available at www.census.gov/quickfacts/ bronxcountybronxboroughnewyork.

U.S. Department of Energy. n.d. Database of state incentives for renewables \& efficiency. Raleigh, NC: NC Clean Energy Technology Center. Available at www. dsireusa.org.

U.S. Department of Energy. 2007. The potential benefits of distributed generation and rate-related issues that may impede their expansion. Washington, DC: Federal Energy Regulatory Commission. Available at www.ferc.gov/legal/fed-sta/ exp-study.pdf.

Wiginton, L. K., Nguyen, H. T., \& Pearce, J. M. 2010. Quantifying rooftop solar photovoltaic potential for regional renewable energy policy. Computers, Environment and Urban Systems, 34(4): 345-357.

World Bank Group. 2016. State and trends of carbon pricing. Washington, DC: World Bank. Available at https://openknowledge.worldbank.org/bitstream/ handle/10986/25160/9781464810015.pdf.

World Economic Forum. 2017. Game changers in the energy system: Emerging themes reshaping the energy landscape. Switzerland: World Economic Forum. Available at www3.weforum.org/docs/WEF_Game_Changers_in_the_Energy_ System.pdf.

Evangelos "Evan" Katsamakas is Professor of Information Systems at Gabelli School of Business, Fordham University. He served as department chair from July 2012 until June 2018 leading the growth of department curriculum, enrollments, and faculty positions. Professor Katsamakas's research analyzes the strategic and economic impact of digital technologies focusing on digital transformation, networks and platforms, data science, business analytics, and fintech. His research interests include economic theory and analytical modeling as well as machine learning and computational modeling of complex business systems. He received the 2018 Dean's Award for Teaching Innovation for his contribution to curriculum innovation. Professor Katsamakas holds a Ph.D. from 
the Stern School of Business, New York University, an M.Sc. from the London School of Economics, and a Computer Science and Engineering degree from the University of Patras, Greece.

Claire Siegrist received a B.S. in Information Systems from the Gabelli School of Business, Fordham University. Her research seeks to apply information technology and data-driven methods to address issues of sustainability in a practical manner. 